\title{
Liquefaction Potential of Silty Sand Surrounding A Bucket Foundation Under Vertical Vibration Load
}

\author{
Lu X. B ${ }^{*}$, Jiao B. T. and Zhang X. H \\ Institute of Mechanics, Chinese Academy of Sciences, Beijing 100080 China
}

\begin{abstract}
To study the liquefaction potential of sand surrounding bucket foundations, centrifuge experiments were carried out. Results have shown that the sand layer around a bucket foundation softens or liquefies under vertical dynamic load when the load amplitude is over a critical value. The liquefaction potential decreased in horizontal direction from the side wall and in vertical direction from the surface of sand layer. The thickness of the completely liquefied sand layer increased with the increase of load amplitude. The affected area which has obvious liquefaction potential is almost the same for a given bucket under different load amplitudes.
\end{abstract}

Keywords: Saturated sand, centrifuge experiment, vertical dynamic load.

\section{INTRODUCTION}

A suction bucket foundation is a closed-top steel tube that is lowered to the seafloor, allowed to penetrate the bottom sediments first under its own weight, and then pushed to full depth with suction force produced by pumping water out of the interior. In the recent years, suction bucket foundations have been increasingly used for gravity platform jackets, jack-ups etc. [1,2]. They also have the potential of being used for several other purposes, such as offshore wind turbines, subsea systems and seabed protection structures [36]. The first advantage of suction bucket foundations is the convenient method of installation and repeated use. For example, a suction bucket foundation with a diameter of $9 \mathrm{~m}$ and a height of $10 \mathrm{~m}$ can be installed in 1 3 hours, by making use of only a pump. The second advantage is that it may mobilize a significant amount of passive suction during uplift under some conditions, although the mobilization of suction mainly depends on the load rate and recommendations are actually to not rely on the suction for design. Up to now, the detail responses of the suction bucket foundations under dynamic loads have remained unknown [7-9]. The dynamic load condition is significant when suction buckets are used as the foundation of an offshore structure. Wave load, iceinduced or wind-induced load cause the foundation to be subjected to cyclic loads $[10,11]$. The lack of experience of bucket foundations with these loads leads to a proposal for a test program intended to gain a deeper understanding. The considerable consumption of expense and time of prototype tests mean that the investigation of the bearing capacity of real scale devices is of limited practicality, while it is much easier to change parameters in small scale tests. The soil type may be varied in these cases. The dimensions of the suction bucket and other process parameters may also be varied con

*Address correspondence to this author at the Institute of Mechanics, Chinese Academy of Sciences, Beijing 100080 China; Tel: 861082544190 ; Fax: 861062561284; E-mail: xblu@imech.ac.cn veniently. Nevertheless, in a small scale test, the problems arise regarding the stress-dependent behavior of soil that the measured loads are so low that measurements are not sufficiently accurate to visualize differences in design. Because the behavior of soil is stress dependent and therefore small scale model test and prototype test can not be subjected to the same stress level to exhibit the same responses. These restrictions can be overcome if performing the tests in a geotechnical centrifuge. In a centrifuge, the soil stresses over a similar depth are the same as in the prototype situation. Centrifugal tests are "model" tests in that the results can be scaled up to the size of full-scale buckets. The main reason to select centrifugal test is for the proper modeling of body forces, which are critically important for the full-scale prototype geotechnical problem, and for the capability of investigating both undrained and partially drained conditions.

Up to now, only a few field tests of suction bucket foundations have been reported in the available literature [12]. A number of investigators have tested scale models of suction buckets in geotechnical centrifuges [13, 14].

Early experience with this technology often involved relatively stiff soils and axial compressive loads applied at the top center of the bucket. Centrifugal tests on suction piles have been reported in the literatures $[15,16]$. Rate dependent load tests on clay at $1 \mathrm{~g}$ were performed by some researchers [17-19].

Later designs for floating structures in deeper water, where horizontal or inclined mooring lines are attached to a bucket, lead to the need for increased lateral capacity. Although the offshore industry is deploying suction buckets in this configuration, a number of design issues remain unresolved $[13,20]$.

The dynamic load is transmitted to the soils by platform and causes the degradation of soil layer's strength and modulus. As a result, the bearing capacity of bucket foundations decreases. Therefore, it is important to clarify the dynamic behavior of bucket foundations under dynamic loads in order to provide practical design methods and parameters $[21,22]$. 


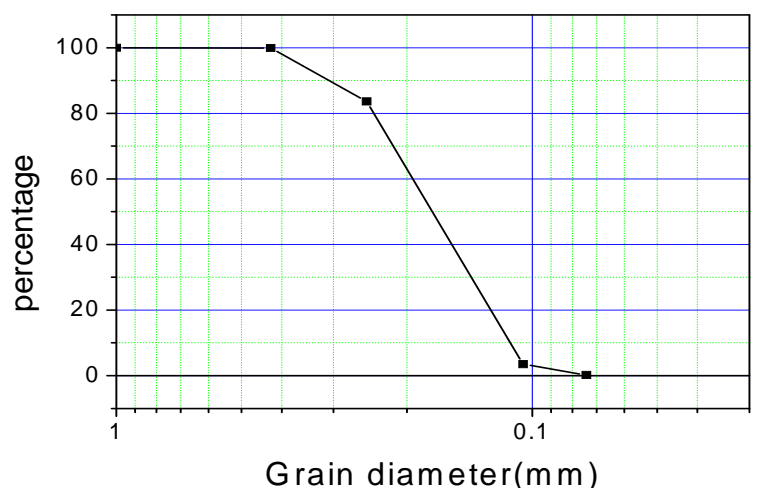

Fig. (1). The grain series curves.

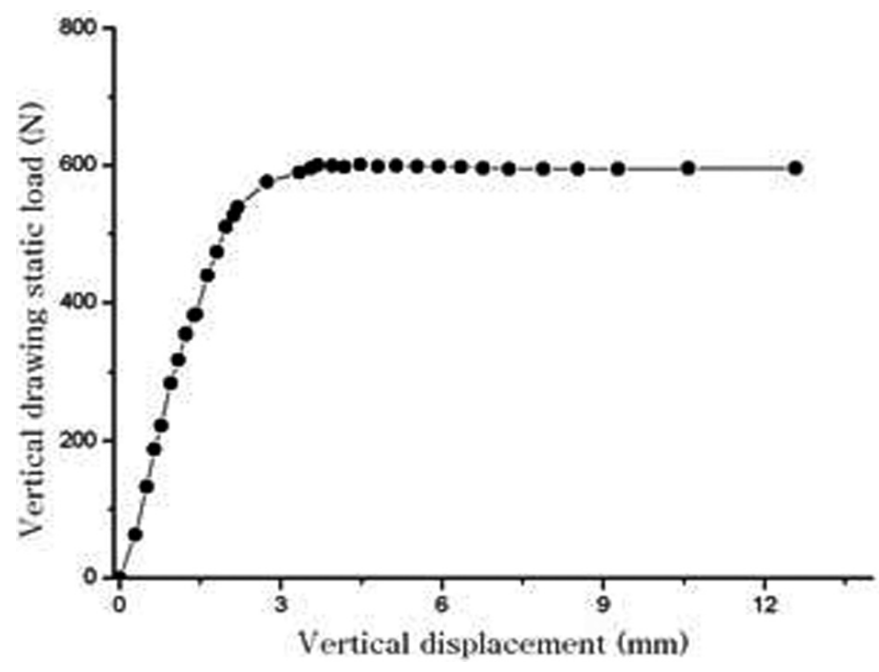

Fig. (2). Static load-displacement.

In this paper, centrifugal experiments are carried out on the responses of silty sand surrounding a bucket foundation under vertical dynamic load. Attention is concentrated on the development of liquefaction potential.

\section{PREPARATION OF EXPERIMENTS}

The experiments are performed in the 50 g-ton centrifuge in Tsinghua University. The maximum of the centrifugal acceleration is $200 \mathrm{~g}$. The payload is $250 \mathrm{~kg}$ under $200 \mathrm{~g}$. Experiments in this paper are all carried out under $80 \mathrm{~g}$, the swelling acceleration increasing from $0 \mathrm{~g}$ to $80 \mathrm{~g}$ lasts $601 \mathrm{~s}$.

The inner size of the model tank used in experiments is $60 \mathrm{~cm} \times 35 \mathrm{~cm} \times 35 \mathrm{~cm}$. The experimental material is fine sand with specific gravity 2.69, average grains diameter (D50) $0.014 \mathrm{~cm}$ and permeability coefficient $1 \times 10^{-4} \mathrm{~cm} / \mathrm{s}$. The grain series is shown in Fig. (1).

In the present experiments, in order to model the permeability, a kind of finer soil is used to reduce the permeability. The silt having a clay content of $3.2 \%$ is adopted so that water could still be used as the pore fluid. The reduction factor of the permeability is about 40, less than 80 (the gravity scale factor). Therefore, the dissipation of pore pressure in the models should be faster than that in the prototype, which might result in lower excess pore pressures in soil layer.

\section{PREPARING OF EXPERIMENTS}

The load device is a hydraulic-electric server system and may output vibration forces with amplitudes of $0-100 \mathrm{~kg}$ and frequencies of $0-20 \mathrm{~Hz}$, or output vibration displacements with amplitudes $0-5 \mathrm{~mm}$ and frequencies of $0 \sim 20$ $\mathrm{Hz}$. The uplift bearing capacity of bucket is $600 \mathrm{~N}$ at the peak displacement [23].

The model bucket has an inner diameter of $6 \mathrm{~cm}$ and a height of $7.2 \mathrm{~cm}$. The thicknesses of the wall and the top cap are both $0.2 \mathrm{~cm}$. A fine pipe with an inner diameter of $0.8 \mathrm{~cm}$ and a length of $10 \mathrm{~cm}$ is welded at the center of the top cap. Six pore pressure transducers (PPT, PDCR82 type) made in Druck Co. (British), are buried in the sand layer around and inside the bucket. The layout of PPTs in test1 4 are shown in Fig. (3). The PPTs are not fixed but suspended in the sand layer. The PPTs may move during experiments because not only they are floated in the sand layer, but also the density is larger than the sand. Table $\mathbf{1}$ gives the final positions of PPTs. It is shown that each PPT settles with the sand. Some PPTs do not just sink vertically, but move some distance laterally. In order to obtain the desired uniform density of the sand layer in the bank, sand specimen is divided into five or six layers according to the positions of PPTs, each layer is compacted gently by hand striking to the given altitude determined by the required dry density.

After the dry sand sample has been prepared, the sand layer is saturated by filling water from the bottom of the tank through a valve. A $0.02 \mathrm{~m}$ thick coarse (and it is over layered by a geofabric) sand layer is laid at the bottom of the tank to

Table 1. The Positions of PPTs after Experiments

\begin{tabular}{|c|c|c|c|c|c|c|c|c|}
\hline \multirow[b]{2}{*}{ PPT } & \multicolumn{2}{|c|}{ Test1 } & \multicolumn{2}{|c|}{ Test2 } & \multicolumn{2}{|c|}{ Test3 } & \multicolumn{2}{|c|}{ Test4 } \\
\hline & D (m) & $\mathbf{L}(\mathbf{m})$ & D (m) & $\mathbf{L}(\mathbf{m})$ & D (m) & $\mathbf{L}(\mathbf{m})$ & D (m) & $\mathbf{L}(\mathbf{m})$ \\
\hline 1 & 1.6 & 0.56 & 1.2 & 0.8 & 0.8 & 1.36 & 1.84 & 0.64 \\
\hline 2 & 1.04 & 3.84 & 0.72 & 4 & 0 & 4 & 2.08 & 3.6 \\
\hline 3 & 0.24 & 8 & 0.72 & 8.8 & 0.16 & 9.6 & 1.44 & 10 \\
\hline 4 & 2.64 & 0.16 & 2.56 & 2.16 & 3.04 & 1 & 2.72 & 0.72 \\
\hline 5 & 4.24 & 1 & 4.56 & 1 & 3.84 & 0.8 & 3.68 & 0.8 \\
\hline 6 & 2.16 & 1 & 1.28 & 1 & 4.8 & 0.8 & 4.88 & 0.8 \\
\hline
\end{tabular}

Note: D: Depth, L: Distance from the sidewall of bucket, "l"denotes the data that this term is not measured. 


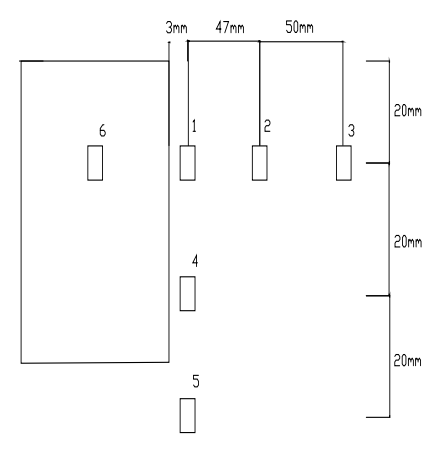

(a) Test1, Test2

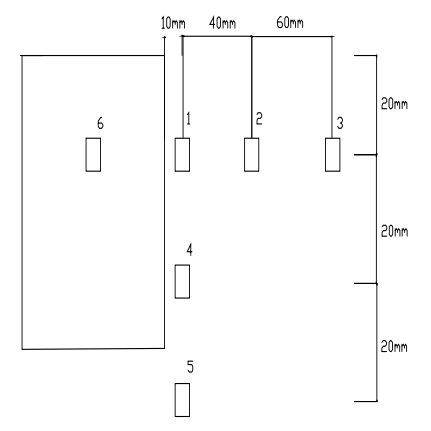

(b) Test3

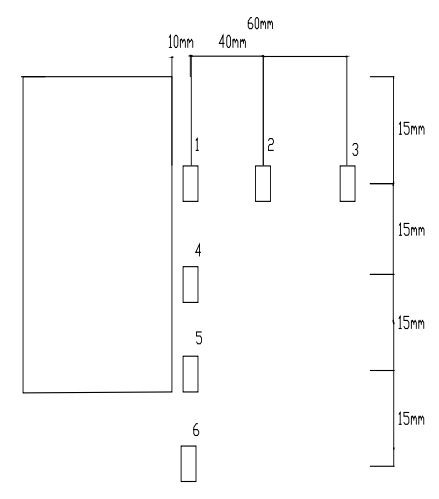

(c) Test4

Fig. (3). Layout of PPT.

allow the water to rise uniformly and prevent the piping. When the water level is $1 \mathrm{~cm}$ over the sand surface, stop filling water and apply vacuum in the sand for 38 hours to increase the saturation degree. The saturated degree is above $98 \%$ in the centrifugal tests, which is tested by measurement of the pore pressure.

After the saturation is completed the consolidation is performed under consolidation pressure of $80 \mathrm{~g}$. The dry densities before and after consolidation are $1520 \mathrm{~kg} / \mathrm{m}^{3}$ and $1600 \mathrm{~kg} / \mathrm{m}^{3}$ respectively, which are measured according to the standards for geotechnical tests in SD 128-84 made by the Chinese Hydraulic and Electric Department when the centrifuge stops. The buoyant unit density is $\gamma^{\prime}=9.71 \mathrm{kN} / \mathrm{m}^{3}$ and the settlement is $0.8 \mathrm{~m}$ (prototype) after consolidation finished. During consolidation, the pore pressure and the displacement are measured to show the development of consolidation. When the settlements and pore pressure do not increase anymore, consolidation stops. It was found through experiments that the consolidation time which the sand density developed to $1600 \mathrm{~kg} / \mathrm{m}^{3}$ was about 40 months. Stop the centrifuge and check the status of transducers and fix the load excitor well to the bucket after finishing the consolidation, and then begin to carry out dynamic experiments.

Four dynamic load experiments with different amplitudes were carried out to study the responses of bucket foundations under vertical vibration load. Load frequencies are all $16 \mathrm{~Hz}$. The amplitude is $2 \mathrm{~mm}$ ( $45 \%$ of static limit displacement (Fig. 2), data are all in model type, $80 \mathrm{~g}$ is used in experiments.) In test 1 , the amplitude is $1 \mathrm{~mm}$ ( $23 \%$ of static limit displacement) in test 2 . the amplitude is first $0.1 \mathrm{~mm}(2.3 \%$ of static limit displacement) for 5 minutes and then is increased to $0.5 \mathrm{~mm}$ ( $11 \%$ of static limit displacement) in test 3 . The amplitude is $0.1 \mathrm{~mm}$ for $340 \mathrm{~s}$ and then is increased to $0.2 \mathrm{~mm}$ in test 4 .

\section{EXPERIMENTAL RESULTS AND ANALYSIS}

\subsection{Pore Pressure}

The history of liquefaction index (liquefaction potential) (Liquefaction index in this paper is defined as the ratio of the measured excess pore pressure to the initial vertical effective stresses at the final position of the corresponding PPT) at different horizontal distances from the side of bucket is shown in Fig. (4). In test 1, the applied load is the largest, hence the structure of sand layer is fast to be destroyed, which leads to the permeability to increase fast, so the liquefaction potential increases at the beginning but decreases soon. When the sand consolidated again, the pore pressure gradually increases again (The largest liquefaction potential at the cycle $\mathrm{N}=30000$ is not a real value but caused by the instability of sand layer, we take the value $\mathrm{N}$ at $\mathrm{N}=1000$ as reference.). In test 2 , the liquefaction potential decreases with the increase of distance from the bucket. The liquefaction index (liquefaction potential) $2 \mathrm{~cm}$ near the bucket (PPT1) is 1.0 , while it is only 0.023 at the position $10 \mathrm{~cm}$ away from the bucket. In test 4 , the applied load is the lowest, thus the liquefaction potential is the smallest (note that the positions of PPTs in test 3 is different with that in tests 1 and 2.). The liquefied soil layer is like a filter which can decrease the load amplitude and waves with some frequencies which can be filtered totally. Thus, load decays with the distance.

The total liquefaction station attained within 2 hours after the dynamic load is applied. This state will keep until the load is removed, which is close to the theoretical solution. The theoretical character time that arrives at a stable state is: $\mu \mathrm{L}^{2} / \mathrm{E} / \mathrm{k}$, in which $\mu$ is the viscosity of water, $\mathrm{L}$ is the characteristic length, $\mathrm{E}$ is the elastic modulus of soil layer, $\mathrm{k}$ is the permeability (unit is $\mathrm{L}^{2}$ ) [24].

The history of liquefaction potential along the depth is shown in Fig. (5). The liquefaction potentials decrease slowly in vertical direction and almost all liquefy in test1. The liquefaction potential changes acutely, this may be the reason that the load is fully carried by pore water after liquefaction, and liquefaction and solidification alternate.

With the decrease of load amplitudes, although the upper sand layer liquefies, the lower part does not. In tests 2 and 3 there is an obvious liquefaction potentials decrease in vertical direction. In test 2 , the liquefaction only occurs at the upper part which is $40 \%$ of the bucket height. In test 3 , again the liquefaction occurs at the upper part which is $30 \%$ of the bucket height.

After liquefaction, the pore pressure change acutely, which shows that the pore water bears nearly the complete load. At the same time, the sand layer liquefies and consolidates alternatively. The pore pressure increases fast to the peak during the first 2 to 3 hours, and then decreases little 

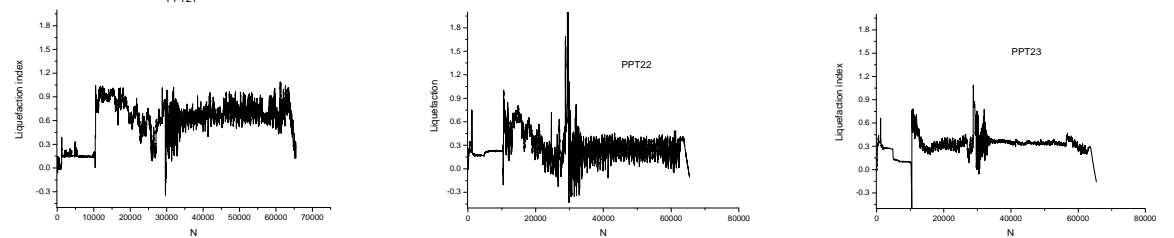

Test1

Test2
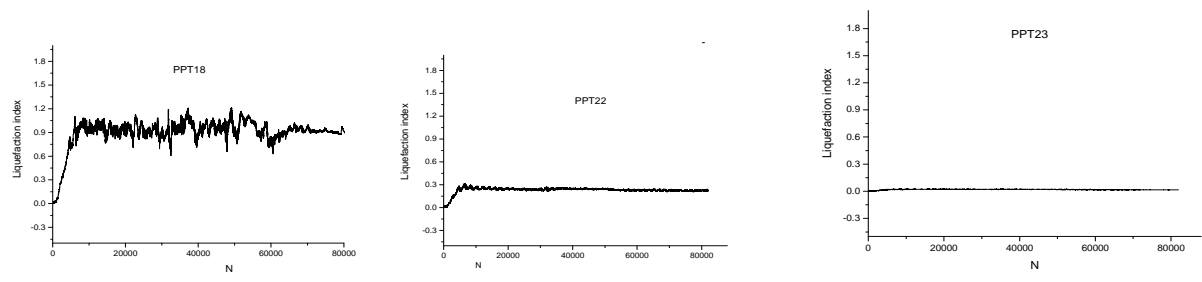

Test3
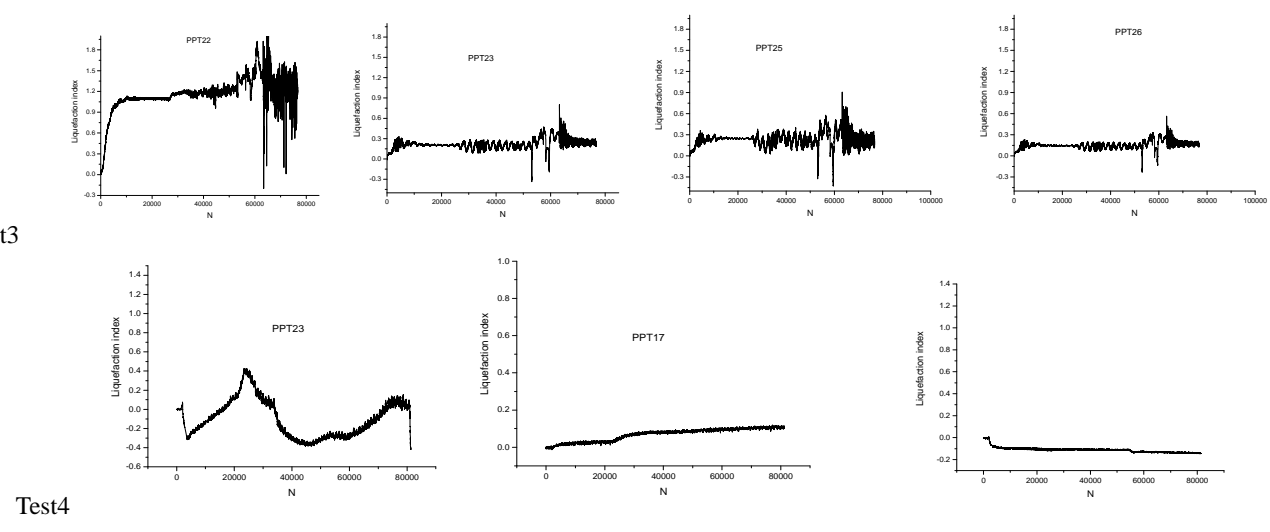

Fig. (4). Development of liquefaction potential in horizontal direction.
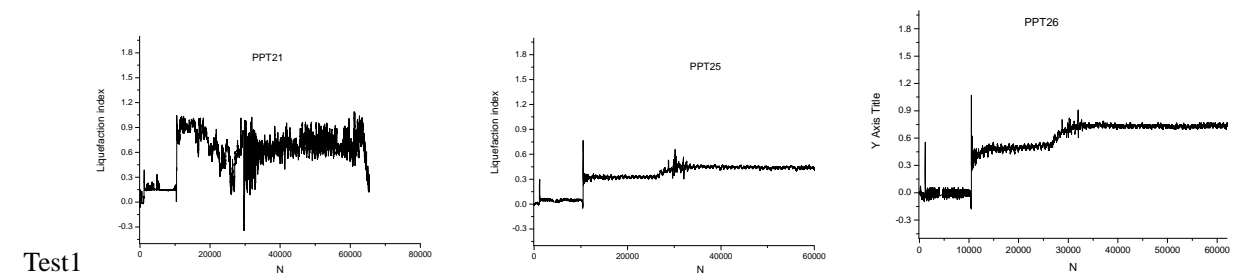

Test2
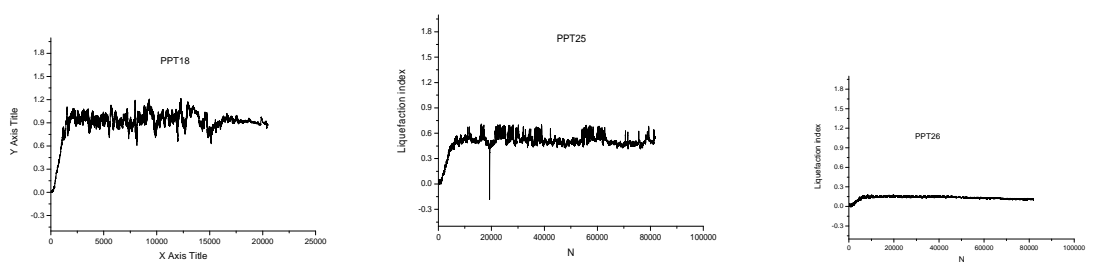

Test3
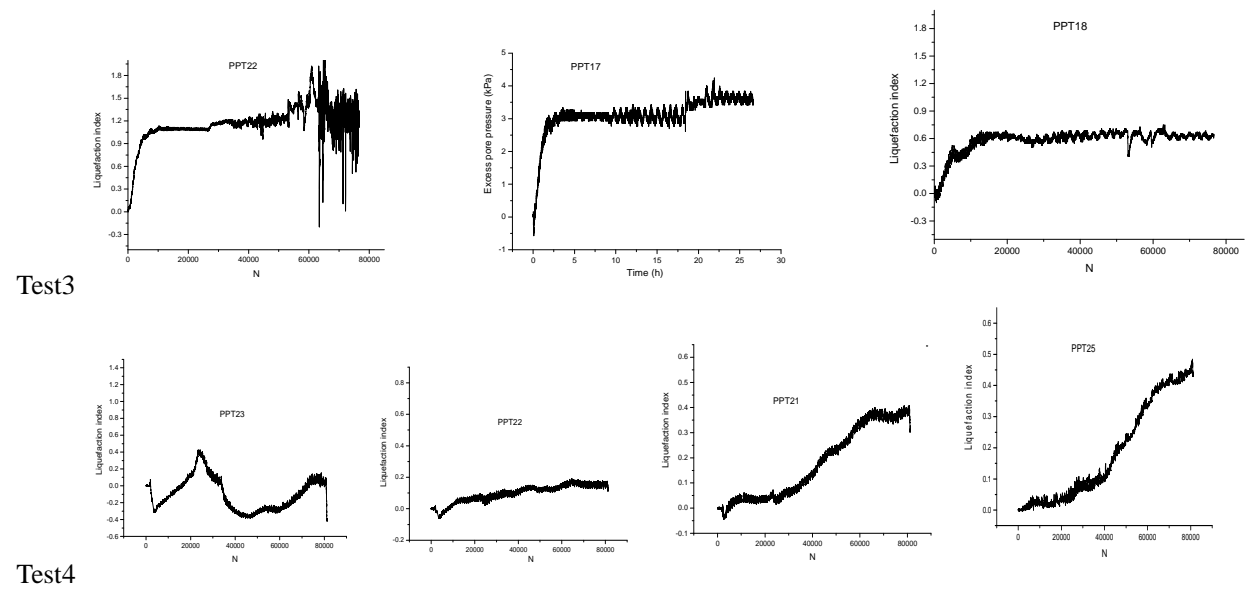

Fig. (5). Development of liquefaction potential in vertical direction. 


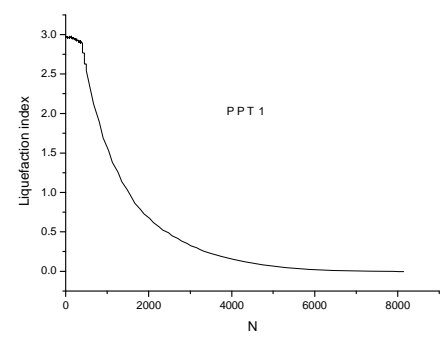

(a) PPT1

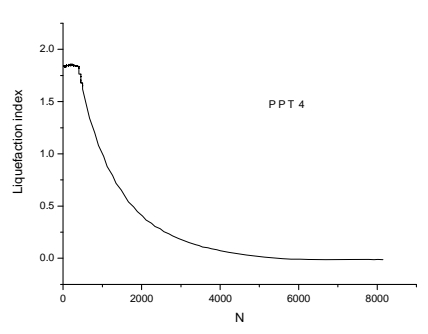

(d) PPT4

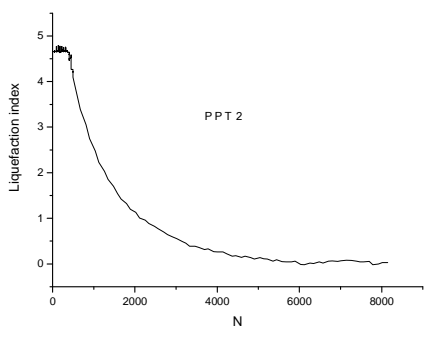

(b) РPT2

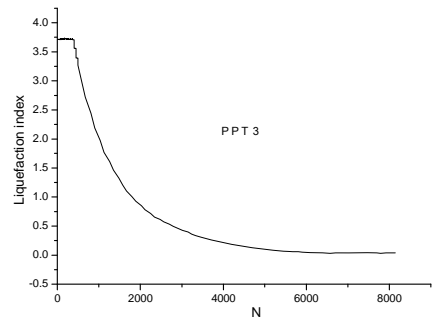

(c) РPT3

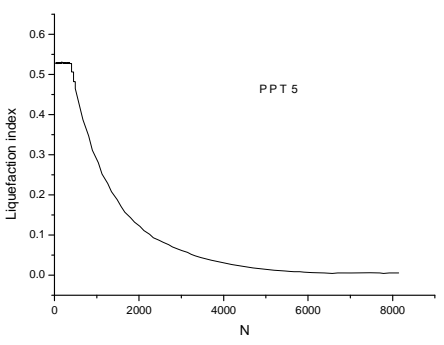

(e) PPT5

Fig. (6). Dissipation of pore pressure after loading is stopped (The time is set as zero when the loading is stopped in this figure).

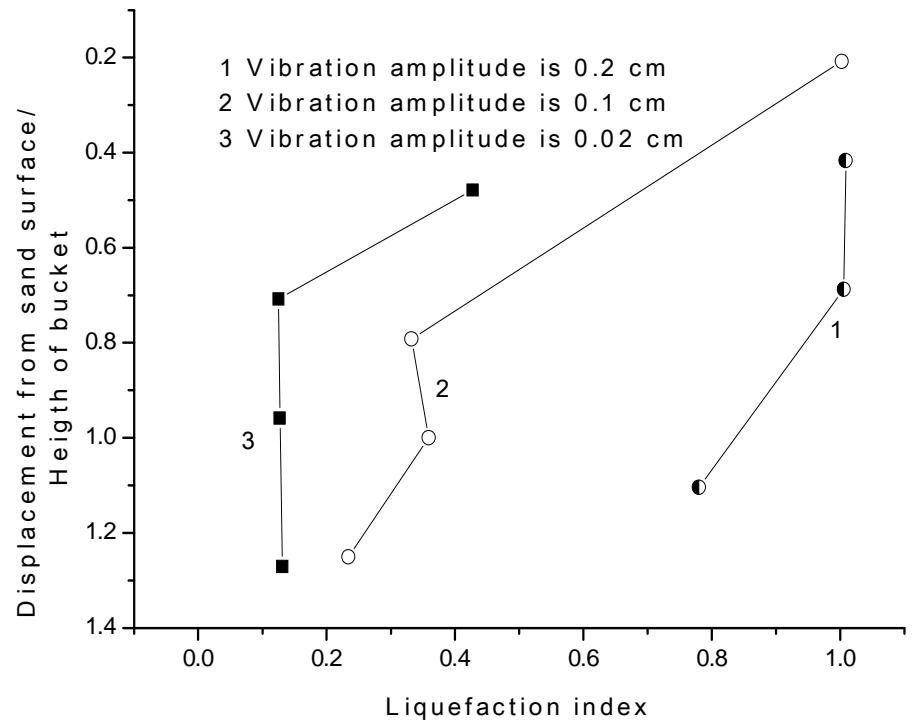

Fig. (7). Distribution of maximum liquefaction index along depth.

during load, which is similar to that under horizontal dynamic load [17] in tests 2 and 3.

Fig. (6) shows the dispersion of liquefaction potential in Test 1 when the load is stopped. Generally, it is shown that the liquefaction potential disperses fast once the load is stopped. The liquefaction potential disappears during 1.5 hours to 1.8 hours. In horizontal direction, the liquefaction potential near the bucket side disappears the most quickly, because the fine grains here are eroded and the permeability increases. At the same time, the gradient of pore pressure here is the largest. In vertical direction, the liquefaction potential at the upper part decreases the fastest. The reason is that on the one hand, the gradient of pore pressure at the upper part is larger than the lower part; on the other hand, the percolation path at the upper part is shorter. According to the consolidation dimensionless time $\mathrm{T}_{\mathrm{V}}=\mathrm{c}_{\mathrm{v}} \mathrm{t} / \mathrm{h}^{2}$, in which $\mathrm{c}_{\mathrm{v}}=\mathrm{k}\left(1+\mathrm{e}_{0}\right) \mathrm{E} / \gamma_{\mathrm{w}}, \mathrm{k}$ is the permeability, $\mathrm{e}_{0}$ is the initial pore ratio, $\mathrm{E}$ is the compressive modulus, $\gamma_{\mathrm{w}}$ is the water density, $\mathrm{t}$ is time, $\mathrm{h}$ is the longest distance for drainage. The duration for the total decrease of excess pore pressure becomes short either for the upper part or the lower part because the permeability increases after liquefaction in these zones [24, 25].

The distribution of maximum liquefaction index in vertical direction near the bucket side under different load amplitude is shown in Fig. (7). (The data is 5 hours after load is applied.). It was shown that the liquefaction index increases with the increase of load amplitude and decreases with the increase of depth. When the load amplitude is $16 \mathrm{~cm}$, the liquefaction index near the surface of soil layer is 0.8 , while it is only 0.1 when the load amplitude is $1.6 \mathrm{~cm}$. When the load 


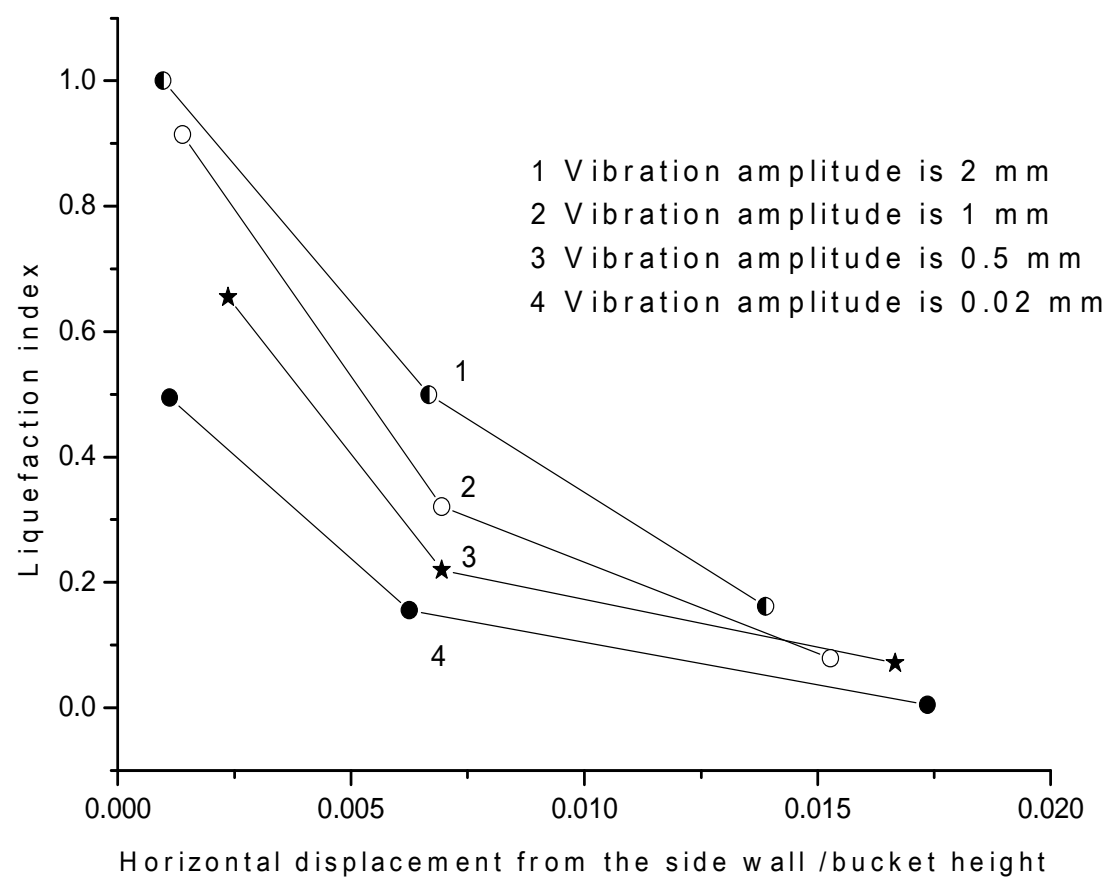

Fig. (8). Distribution of maximum liquefaction index in horizontal direction.

amplitude is huge almost all are liquefied near the bucket. However, only the upper part is liquefied when the load amplitude is small (Jiao et al., 2010).

Fig. (8) shows the distribution of liquefaction index in horizontal direction under different load amplitudes. It was shown that with the increase of load amplitude, the liquefaction index at each point in horizontal direction increases. The reason is that with the increase of load amplitude, the disturbed amplitude and the zone of soil layer increase, which leads to the increase of liquefaction potential and effected zone.

\section{CONCLUSIONS}

Centrifugal experiments were carried out to simulate the responses of bucket foundation under vertical dynamic load. It was shown that the liquefaction potential decreased from the side wall of the bucket and is limited in a zone around the bucket under vertical dynamic load. The liquefaction potential increased with the increase of load strength. The liquefaction potential quickly increased to the peak value during the first 1 2 hours (prototype), then decreased little or keep constant during load. The liquefaction potential decreased fast during 1.5 hours to 1.8 hours once the load is stopped. In horizontal direction, the liquefaction potential near the bucket decreased the fastest.

\section{CONFLICT OF INTEREST}

The authors confirm that this article content has no conflicts of interest.

\section{ACKNOWLEDGEMENTS}

This program is supported by the fund of Chinese Ocean Oil Co. and Chinese Academy of Sciences"_KJCX2-SWL03-01"(40025103) and National Natural Science Fund(No. 10772182)

\section{REFERENCES}

[1] E. C. Clukey, M. J. Morrison, J. Garnier, and J. F Carte, "The response of suction caissons in: normally consolidated clays to cyclic TLP loading conditions", In: Proc. Offshore Tech. Conf., OTC 7796, 1995, pp. 909-918.

[2] H. G. B. Allersma, F. J. A. Plenevaux, and J. F. P. C. M. E. Wintgens, "Simulation of suction pile installation in: sand in: a geocentrifuge", In: 7th Int. Offshore and Polar Eng. Conf., 1, 1997, pp. 761-765.

[3] G. T. Housby, and B. W. Byrne, "Suction caisson foundations for offshore wind turbines and anemometer masts", Wind Eng., 24, no. 4, pp. 249-255, 2000.

[4] B. W. Byrne, and G. T. Housby, C. M. Martin, and P. M. Fish, "Suction caisson foundations for offshore wind turbines", Wind Eng., 26, no. 3, pp. 145-155, 2002.

[5] B. W. Byrne, and G. T. Houlsby, "Experimental investigations of the responses of suction caissons to transient combined loading", ASCE J. Geotech. Geoenviron. Eng., 130, no. 3, pp. 240-253, 2004

[6] K. H. Andersen and H. P. Jostad, "Foundation design of skirted foundations and anchors in: clay". In: Proc Offshore Tech. Conf., Houston, Texas, OTC 10824, 1999,pp. 1-10.

[7] D. Senpere, and G. A. Auvergne, "Suction anchor piles-a proven alternative to driving or drilling", In: Proc. Offshore Technology Conference, OTC4206, 1982, pp. 483-493.

[8] P. M. Aas, and K. H. Andersen, "Skirted foundation for offshore structure", In: 9th Offshore South East Asia Conf., Singapore, 1992. Singapore: World Trade Center Singapore, 1-7, 1992

[9] W. Dyme, and G. T. Houlsby, "Drained behavior of suction caisson on very dense sand", In: Proc. Offshore Tech. Conf., OTC10994, 1998, pp. 765-782

[10] T. L. Tjelta, J. Hermstad, and E. Andenaes, "The skirt piled gullfaks c platform installation", In: Proc. Offshore Tech. Conf. ,OTC6473, pp. 453-462, 1990

[11] A. Bye,C. Erbrich, K. Earl, B. Rognlien, A. Engineering, T. I. Tjelta, "Geotechnical design of bucket foundation", In: Proc. Offshore Tech. Conf. ,OTC7793, 1995, pp. 869-883.

[12] T. I. Tjelta, T. R. Guttormsen, and J. Hermstad, "large-Scale penetration test at a deepwater site", In: Proc. Offshore Tech. Conf., OTC 5103, 1986, pp. 201-212.

[13] E. C. Clukey, "Suction caisson design issues", In: Proc. OTRC 2001 Inter. Conf. Geotech., Geol. and Geophy. Properties of Deepwater Sediments, Houston, 2001, pp. 163-181.

[14] M.J.Cassidy, B.W.Byrne and M.F.Randolph, "A comparison of the combined load behavior of spudcan and caisson foundations on soft 
normally consolidated clay." Geotechnique, 54, no. 2, pp. 91-106, 2004.

[15] L.D.Fuglsang and J.O.Steensen-Bach, "Breakout resistance of suction piles in clay." In: Proc. Int. Conf.: Centrifuge 91. H. Y. Ko and F. G. Mclean Eds., A.A. Balkema, Rotterdam: The Netherlands, 1991, pp.153-159.

[16] L. Xiaobing, W. Yongren, J. Bintian, and W. Shuyun, "Centrifugal experimental study of suction bucket foundations under dynamic loading." ACTA Mech. Sinica., vol. 23, pp. 689-698, 2007.

[17] W.C. Jones, M. G. Iskander, R. E. Olson, A. D. Goldberg. "Axial capacity of suction piles in sand", In: Proc. 7th Int. Conf. On the Behav Offshore Struct., C. Chryssostomidis, Ed. USA, Pergamom, 1994, pp. 63-75.

[18] Wang Yihua, Lu Xiaobing, Wang Shuyun and Shi Zhongmin, "The responses of the bucket foundation under horizontal dynamic loading." Ocean Eng., vol. 33, pp. 964-973, 2006.

[19] J. O. Steensen-Bach, "Recent model tests with suction piles in: clay and in: sand", In: Proc. Offshore Tech. Conf., Houston, USA, OTC6844, 1992, pp. 323-330.
[20] A. M. Luke, A. F. Rauch, R. E. Olson and E. C. Mecham, "Components of suction caisson capacity measured in: axial pullout tests", Ocean Eng., vol. 32, pp. 878-891, 2005.

[21] H.Y. Ding, L. Qi and X.Z.Du, "Estimating soil liquefaction in iceinduced vibration of bucket foundation." J. Cold Reg. Eng., 17, no. 2, pp: 60-67, 2003.

[22] Lu Xiaobing, Zheng Zhemin, and Zhang Jinlai, "Progress in the study on the bucket foundation of offshore platform." Adv. Mech. (in Chinese), vol. 33, no. 1, 27-40, 2003.

[23] B. T. Jiao, X. B. Lu, Z. M. Shi and J. H. Zhang, "Centrifuge experimental study on the bucket foundation responses under vertical vibration load." China Offshore Platform (in Chinese), vol. 21, no. 5, pp.13-15, 2010

[24] X. H. Zhang, X. B. Lu and S. Y. Wang, "Dimensionless analysis of the simulation of bucket foundations under dynamic load." Open Ocean Eng. J., vol. 3, pp. 56-62, 2010,

[25] R.N.Taylor, "Geotechnical centrifuge technology." Blackie Academic \& Professional: London, 1995.

Received: June 18, 2012

Revised: July 30, 2012

Accepted: August 02, 2012

(C) Lu et al.; Licensee Bentham Open.

This is an open access article licensed under the terms of the Creative Commons Attribution Non-Commercial License (http://creativecommons.org/licenses/by-nc/3.0/) which permits unrestricted, non-commercial use, distribution and reproduction in any medium, provided the work is properly cited. 